\title{
DECOR: The Database of Educational Crystallographic Online Resources, Updates and Prospectus
}

\author{
M Zdilla ${ }^{1}$ \\ ${ }^{1}$ Chemistry, Temple Univ, Philadelphia, PA \\ mzdilla@temple.edu
}

The Database of Educational Crystallographic Online Resources (DECOR) is the worlds first repository for educational resources for the teaching of crystallography and diffraction. The site, available at decor.cst.temple.edu, permits the sharing and downloading of educational resources such as practice problems, visual aids, animations, and more. The site is currently organized into three basic resource layouts: 1) Resources by Type, where visitors can browse for homework problems, presentations slides, or animations across topics. 2) Resources by Topic, where visitors can look for resources relating to particular subject matter such as the reciprocal lattice, scattering, or symmetry. 3) Links, which sends visitors to other sites that provide convenient resources for crystallographic education. The purpose of the poster is to make attendees aware of this teaching resource, and to present the current state of the site, and plans to upgrade and enhance it in the near future.

Acta Cryst. (2020). A76, a196 